\title{
The Poolean Consensus Model: The Strategic Scope of Monetary Policy
}

\author{
Friedrich L. Sell ${ }^{1}$, Beate Sauer ${ }^{2}$, Marcus Wiens ${ }^{3}$ \\ ${ }^{1}$ Economics and holds the Chair of Macroeconomics at the Department of Economics, Fakultät für Wirtschafts- und \\ Organisationswissenschaften, Bundeswehr University Munich, Neubiberg, Germany \\ ${ }^{2}$ Research Assistant at the Chair of Macroeconomics, Fakultät für Wirtschafts- und Organisationswissenschaften, Bun- \\ deswehr University Munich, Neubiberg, Germany \\ ${ }^{3}$ Department of Economics, Fakultät für Wirtschafts- und Organisationswissenschaften, \\ Bundeswehr University Munich, Neubiberg, Germany \\ E-mail: \{friedrich.sell, beate.sauer,marcus.wiens\}@unibw.de \\ Received June 2, 2010; revised July 8, 2010; accepted July 12, 2010
}

\begin{abstract}
Some years ago (before the outbreak of the financial crisis) most of the major central banks - in generalshifted to interest rate control. But does this fact render obsolete the IS-LM scheme, which is apparently tied to money supply control? And isn't it necessary to find a solid basis for interest rate control instead of just following ad hoc policy functions? This paper is a sensible approach based on the important pioneering work of William Poole [1], which shows firstly that the static IS-LM framework can be further developed for the case of interest rate control and that secondly the current financial crisis and especially the policy reactions of central banks can be explained. Thirdly also the optimization behavior of central banks can be adequately represented in the dynamic version of our model framework. Especially in times of financial and economic crises (when central banks possibly switch their monetary policy instruments back to quantitative easing), it seems to be very helpful to be able to display both interest rate control and money supply control within one single model framework. Our analysis will show that retaining the LM curve is both practical and indispensable for didactic and analytical reasons.
\end{abstract}

Keywords: Monetary Policy, Economic and Financial Crisis, Quantitative Easing, New Keynesian Macroeconomics, Standard Macroeconomic Model, William Poole

\section{Introduction}

Some years ago (before the outbreak of the financial crisis) most of the major central banks - in general—shifted to interest rate control. But does this fact render obsolete the IS-LM scheme, which is apparently tied to money supply control? It seems that some economists think so and replace the LM curve with a policy function ("MP", "TR"). We will show why this is not at all necessary. The Poolean model is able to present and compare both interest rate control and money supply control within one model framework. It is even possible to decide what policy is more advantageous if either money demand shocks or output demand shocks occur.

Furthermore, a lot of economists argue that the current financial crisis and especially the policy reactions of central banks cannot be explained with common macroeco- nomics. But is it really true, that neither a diagnosis, nor an analysis nor a therapy of the crisis is possible with standard macro-models? No, it is not! We will explain this fact with the Poolean model as well.

Therefore the rest of our paper is structured as follows:

Section 2 presents details of the debate between the advocates of the "macroeconomic standard model" and "New Keynesian Macroeconomics" to emphasize the differences and to show why the LM curve still is important, even if central banks control the interest rate instead of the money supply. Therefore we blind out the current crisis. In Section 3 we present the model based on the important pioneering work of William Poole [1], which shows that not only the static IS-LM framework can be further developed for the case of interest rate control, but also the optimization behavior of the central banks can be adequately represented in the dynamic version of this model framework without abolishing the money market 
equilibrium. This seems necessary because it can be assumed that central banks will shift back to interest rate control when the crisis is overcome. In Section 4 we develop a solid basis for central banks' interest rate decisions instead of using ad-hoc interest rate rules. In this case, the following applies: Depending on the priority placed on output target and inflation target, the central banks will choose different interest rates. In this way, the interest rate control behavior of modern central banks can be microeconomically justified without having to assume $a$ priori that a Taylor rule is followed. Especially with the monetary policy switch of major central banks it is essential to be able to use one model to explain both money supply control and interest rate control.

The paper ends with some conclusions in Section 5.

\section{The Debate between the Advocates of the "Macroeconomic Standard Model" and "New Keynesian Macroeconomics"}

Traditional-but also well-established-instruments of macroeconomic analysis, especially the IS-LM framework and the static AS-AD framework, have become a target of considerable criticism because almost all major central banks changed their monetary policy to interest rate control. In the meantime, some textbooks do not work with the LM curve any more, just the appendix is good enough to explain this money market equilibrium analysis. The LM curve as one of the basic instruments in modeling the money market fades out of macroeconomics education. But can it make sense to blind out explicit money market equilibria within monetary macroeconomics by assuming a priori that central banks follow Taylor rules and by merely applying policy functions ("MP", "TR"), as advocates of "New Keynesian Macroeconomics" do?

In detail: Firstly, the advocates of "New Keynesian Macroeconomics" criticize the ambiguity of the axis label of the ordinate for the IS-LM scheme. For the goods market equilibrium, it should have to be the real interest rate, while for the money market equilibrium only the nominal interest rate is adequate. This dilemma could only be overcome by assuming, at the same time, constant prices and inflation expectations of zero in the short-run. Even if the latter was accepted, the former could only apply to the extremely special case of a horizontal AD function. Secondly, it is criticized that the mere static model framework is inadequate because, in reality, growth rates of prices (inflation rate) and output, but not the level of prices and output are taken into account.

The mentioned arguments sound good, but they are not really substantive. For example: If New Keynesians insist on the sluggishness of output prices (cf. Romer [2]) in the short-run, it is only reasonable to postulate sluggish inflation expectations within the conventional IS-LM scheme in connection with the static AS-AD analysis as well; thus, the Fisher interest parity continues to hold, even if changes in the output price level occur. Incidentally, the traditional static AS-AD analysis discusses one-off rises or reductions in the price level and not a process of continuing price increases, i.e. inflation. However, only the latter can also trigger positive inflation expectations and/or changes therein.

Even if all major central banks should have abandoned any money supply control (which is not the case at all in the current crisis), it would remain important from a theoretical point of view to regard the pursuit of a money supply control as a reference solution, especially if there are strong indications that it has advantages in comparison with an interest rate control under certain conditions (cf. Sell [3]). For this purpose, a theoretical framework is required which permits an undistorted comparison of both concepts. If a central bank controls its money supply, there is a money supply target $\overline{\mathrm{M}}$ or a target growth rate $\bar{m}$, which can be reached with the interest rate as monetary policy instrument. Does a central bank follow an interest rate target $(\bar{\imath})$ however, it is able to realize it via its money supply. The IS-LM analysis and (as we found out later) also the (static) AS-AD analysis provide exactly this type of framework, as was already shown by William Poole [1] 38 years ago. An IS-LM analysis "relieved" of the explicit money market (equivalent to an IS-LM analysis without the LM curve) in favor of a monetary policy rule by the authors of the "New Keynesian Macroeconomics," including Clarida et al. [4], Romer [5], Romer [2], Walsh [6] and others, however, is inappropriate for this purpose. Above all, it has apparently been "forgotten" that the explicit (rather than only an implicit) money market equilibrium is indispensable for blinding out - through Walras' Law - the capital market. This is the only way to simultaneously consider four macroeconomic equilibria where only three of them are analytically explicitly and completely formulated.

But our article neither wants to take a position against modeling policy rules in macroeconomics education on principle (therefore, it will ignore the advantages specified by Romer [5]) nor does it want to discuss in depth the disadvantages of the "New Keynesian Macroeconomics" as Friedman [7] does. We want to emphasize primarily the comparative advantage of William Poole's integrative approach.

The objection that William Poole was only interested in the rule of a constant nominal interest rate while Taylor's and related rules are about regulations for changing the nominal interest rate to influence the real interest rate is not conclusive. Due to comparative statics within his model - and naturally even far more by a dynamization of the approach - the Poolean model can also be designed for a rule of the interest rate variation and/or for 
change rates of the price level and of the output. Especially if the conviction prevails that modern central banks do not (or no longer) pursue any money supply control, but interest rate control (it really was the case until the start of the economic crisis in 2008 and most likely it will be the case again after the crisis), it appears outright bizarre to associate the European Central Bank's (ECB) or US-Fed's monetary policy with a Taylor rule as an exante strategy in the new millennium. The ECB largely co ncentrates on stabilizing the price level while the Federal Reserve has already stepped in for the second time since 2001 to contain damage during and after a financial market crisis. Therefore a Poolean interest rate control seems to be appropriate in a twofold way: Not only does it retain the concept of the explicit money market equilibrium, it can also be oriented contractively or expansively depending on the requirements, irrespective of whether the acting central bank is committed exclusively to the aim of price level stability or also to the overall economic output and/or the aim of creating employment.

\section{The Static Poolean Consensus Model in the Short-Run}

Figure 1 shows a simple money market in which the "traditional" money supply control of central banks can be described: With a short-run (sluggish) output price level $\left(\mathrm{P}_{0}\right)$, the central bank aims at the (nominal) money supply target $\bar{M}$; for this purpose, interest rate level $i$ is a suitable means. If fluctuations in the money demand - due to increases in income $(\mathrm{Y})$ or shocks $(\mathrm{u})$ - occur between $\mathrm{L}_{0}$ and $\mathrm{L}_{1}$ and/or $\mathrm{L}_{2}$ then the central bank will continue to reach its target money supply by adapting the (hence endogenous) interest rate level to the new amount $\mathrm{i}_{1}$ and/or $\mathrm{i}_{2}$.

In Figure 2, we can describe the interest rate control conducted by central banks in accordance with Poole (1970): In order to achieve the desired interest rate $\mathrm{i}$, the central bank must-for a specific money demand $\mathrm{L}_{0}$ - now provide money supply $\mathrm{M}_{0}$. If fluctuations in the money demand occur between $\mathrm{L}_{0}$ and $\mathrm{L}_{1}$ and/or $\mathrm{L}_{2}$ (for similar reasons as described above), then the central bank would have to adjust the money supply toward level $\widetilde{\mathrm{M}}_{1}$ and/or $\widetilde{M}_{2}$. On the other hand, the central bank is still able to adapt its key interest rate to a changed environment and adopt a more expansive (contractive) policy. For a target interest rate of $i_{1}\left(i_{2}\right)$ it must stear the money supply toward level $\mathrm{M}_{1}\left(\mathrm{M}_{2}\right)$. Interest rate control and money supply control exhibit different comparative advantages: Interest rate control proves especially favorable if money demand shocks occur. These are not uncommon during the introduction of a currency union. That is why in 1999 the ECB gave priority to an interest rate control in contrast to the money supply control of the Deutsche Bundesbank. Already in the 1970s William Poole showed the comparative advantages of that policy compared to money supply control when money demand shocks occur.

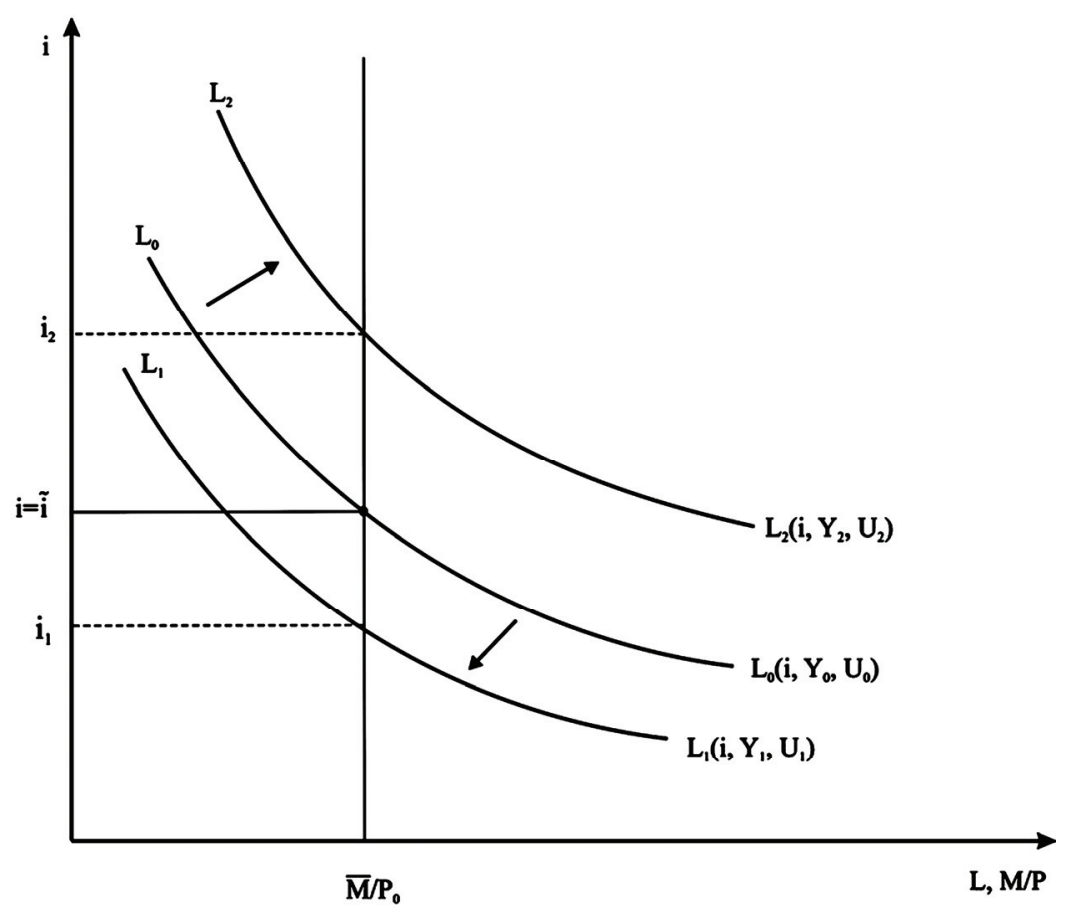

Figure 1. Money supply control according to W. Poole (1970). 
As shown in Figure 3, the pursuit of interest rate control permits, as a general rule, to completely prevent potential output fluctuations $\left(\mathrm{LM}_{3}\right.$ (i)), while the pursuit of money supply control cannot prevent shifts of the LM curve $\left(\mathrm{LM}_{1}\right.$ and/or $\left.\mathrm{LM}_{2}\right)$; thus corresponding output fluctuations in interval $Y_{1}-Y_{2}$ have to be accepted.

The comparative advantages show a completely diff- erent distribution when shocks to the output demand disturb the initial equilibrium: As demonstrated in Figure 4, the pursuit of money supply control reduces the potential output fluctuations to interval $\mathrm{Y}_{3}-\mathrm{Y}_{4}$, while the orientation of the monetary policy towards interest rate control extends the interval to the new limits $\mathrm{Y}_{5}-\mathrm{Y}_{6}$, which signify a much larger output fluctuation.

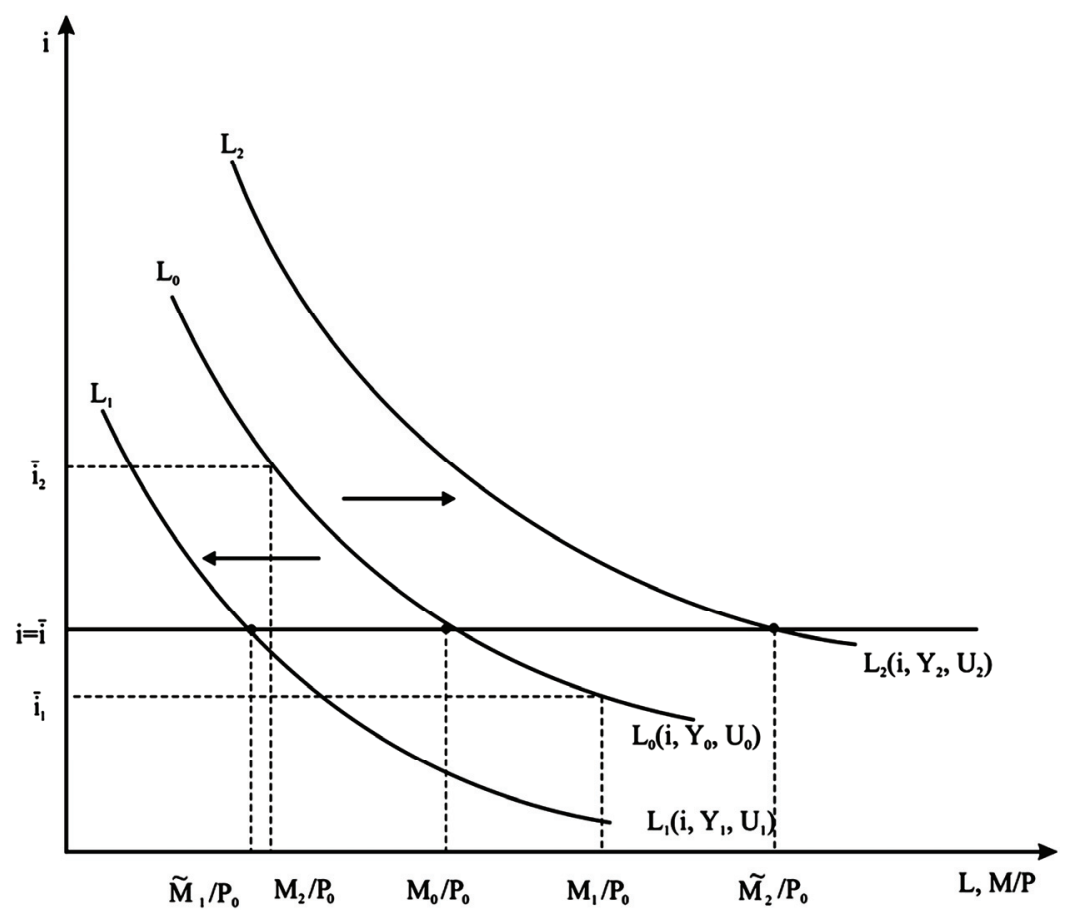

Figure 2. Interest rate control according to W. Poole (1970).

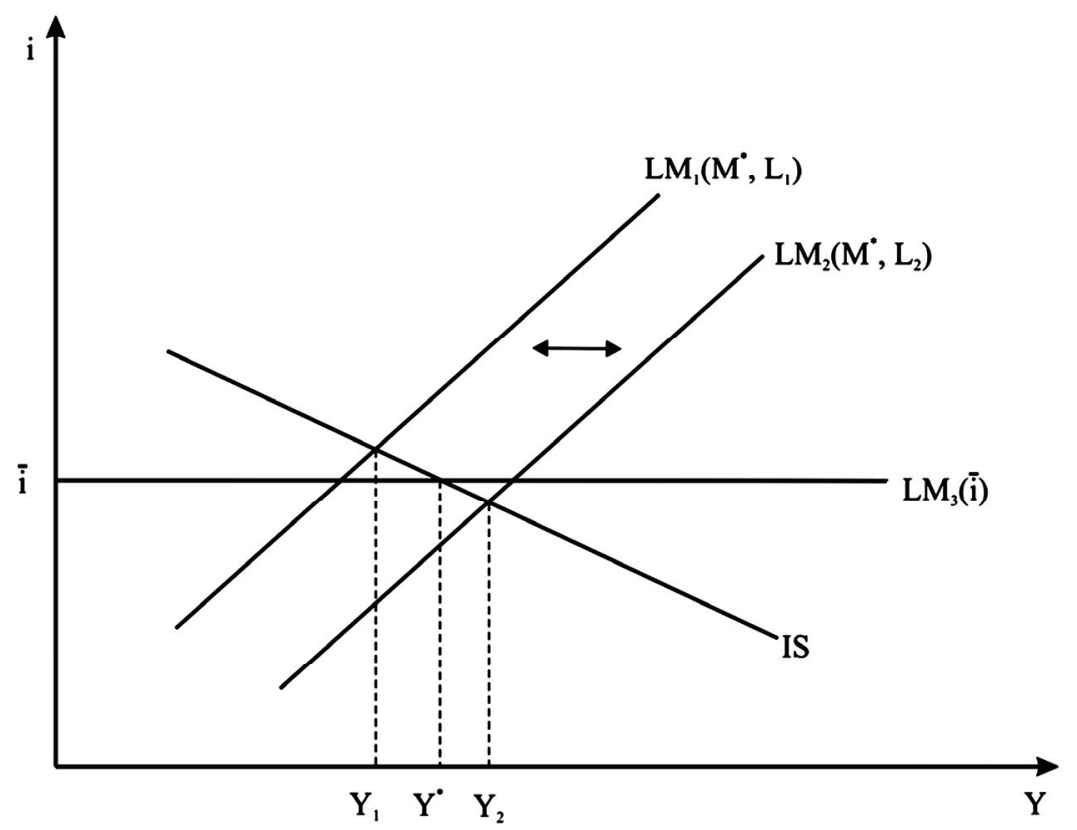

Figure 3. Output stabilization in the case of money demand shocks according to W. Poole (1970). 


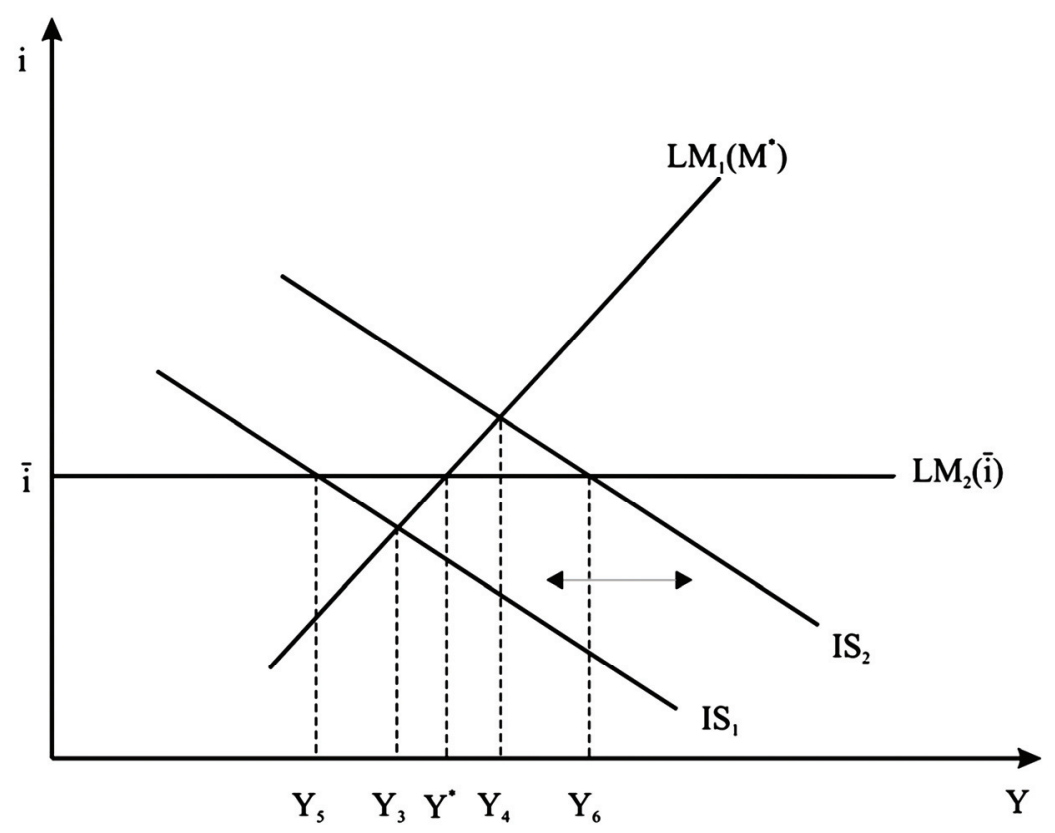

Figure 4. Output stabilization in the case of output demand shocks according to W. Poole (1970).

The current crisis is nothing other than an output demand shock where money supply control is more advantageous. All major central banks followed Poole's recommendation and shifted away from interest rate control to quantitative easing. To avoid a so-called zero-interestrate-policy, the US-Fed and the Bank of England changed their instruments when reaching the 0.25 and 0.5 percent threshold, respectively. Because of the blocked transmission channel (reduction of the key interest rate is not passed through to private economic agents by commercial banks/does not lead to lower interest rates on money markets), both central banks bought government securities and/or toxic assets to expand the monetary basis via money printing. This quantitative easing cannot be demonstrated without the LM curve. When the effects of the current financial crisis will be overcome, interest rate control is again conceivable as the adequate monetary policy instrument.

The effectiveness of monetary and fiscal policies can be examined in conjunction with the static AS-AD scheme (as it is described in Blanchard [8]) without abandoning the LM curve, where the central bank pursues - in the sense of Poole, but also in the sense of the "New Keynesian Macroeconomics"-interest rate control in an endogenous money supply environment.

We will take the following, strongly simplified structure as the basis model:

Let $Y$ be the output of the economy, $A_{a}$ the domestic autonomous absorption, $h$ the marginal propensity to invest and $r$ the real interest rate. Then the IS curve takes the common form

$$
Y=\alpha\left(A_{a}-h r\right)
$$

where $\alpha \equiv \frac{1}{1-c+c t}$, with $c$ being the marginal propensity to consume and $t$ being the rate of taxation.

The money market is represented by the LM curve

$$
i=\frac{1}{j}(k Y-M)+u,
$$

with $i$ denoting the nominal interest rate, $k$ the transaction motive of the money demand, $j$ the speculation motive of the money demand, $M$ the real money supply, and where $u$ is a shock term distributed with zero mean and variance $\sigma^{2}$.

The real money supply is defined as

$$
M=\frac{M^{n}}{P},
$$

where $M^{n}$ is the nominal money supply and $P$ stands for the price level.

The central bank's nominal interest rate control can be written as:

$$
i=i^{*}
$$

The right-hand side of Equation (4) replaces the righthand side of the LM curve, because the central bank compensates for fluctuations in the money demand as a consequence of income changes and/or under the influence of shocks in such a way that its interest rate concept materializes. As no distinction is made between the nominal and the real interest rates within the short-run $(i=r)$, $i^{*}$ can directly be inserted in the IS curve (1):

$$
Y=\alpha\left(A_{a}-h i^{*}\right)
$$


Thus, the AD curve generated runs vertically and is therefore completely price inelastic. In the case of an increase (a reduction) in the interest rate, it shifts in a parallel manner to the left (right):

$$
\frac{\partial Y}{\partial i^{*}}=-\alpha h<0
$$

In conjunction with a very simple AS function (cf. Dornbusch/Fischer [9])

$$
P=P_{-1}\left[1+\gamma\left(Y-Y^{\text {nat }}\right)\right],
$$

with $\gamma$ as a weighting coefficient and $Y^{\text {nat }}$ as the natural output level, a compact AS-AD scheme can be obtained in the case of interest rate control, but without abandoning the money market equilibrium concept.

An expansive (contractive) monetary policy (Figure 5) determines a lower (higher) interest rate compared to the initial level $\mathrm{i}_{0}$, which causes the entire LM curve to shift down (up) to the new interest rate level $i_{1}\left(i_{2}\right)$. In the aggregated supply and demand chart, the monetary policy results in an excess demand in the amount of $\mathrm{Y}_{1}-\mathrm{Y}_{0}$ (excess supply in the amount of $\mathrm{Y}_{0}-\mathrm{Y}_{2}$ ) for the initial price level $\mathrm{P}_{0}$ because of the short-run sluggishness of prices. The subsequent price increase to $\mathrm{P}_{1}$ (price reduction to $\mathrm{P}_{2}$ ) lowers (raises) the value of the real money supply and/or the equally high real balance. As a consequence (in the medium-run), interest rates will rise to $i_{1}{ }_{1}$ (fall to $i_{2}{ }_{2}$ ), provided the central bank does not compensate for this effect. In both cases, the desired higher income/higher price level (lower income/reduced price level) will be achieved.

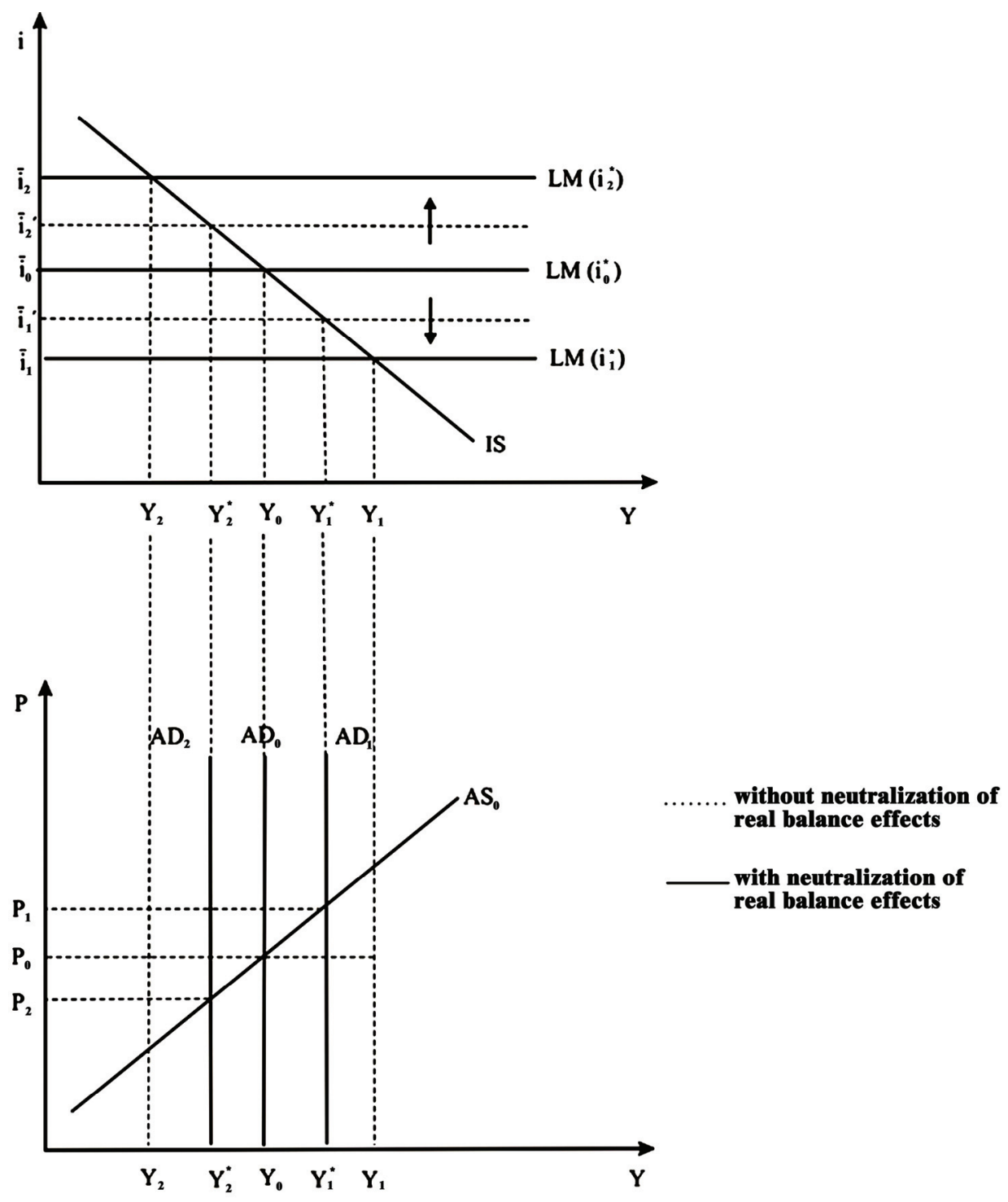

Figure 5. Expansive/contractive monetary policy in the case of interest rate control. 
Finally, in Figure 6, the options of fiscal policy are discussed for the case of interest rate control. An expansive (contractive) fiscal policy creates (analogous with the above) an excess demand (excess supply) in the aggregated supply and demand chart for the initial price level $\mathrm{P}_{0}$. The subsequent price increase (price reduction) lowers (raises) the value of the real money supply and/or the equally high real balance. As a consequence (in the medium-run), interest rates will also rise to $i_{1}$ (fall to $i_{2}$ ) and the LM curve will shift up (down) accordingly, again provided the central bank does not compensate for this effect. In both cases fiscal policy now achieves the desired higher income/higher price level (lower income/ reduced price level).

By the way, it is possible to add the upward sloping Fleming-Mundell ZZ curve to the existing description and, hence, to shift to the open economy very easily (cf.
Sell [3]). The use of Poole's approach in an open economy case to explain and compare the different central bank policies is doable as well. Sell/Kermer [10] did a formal analysis of possible losses caused by either a cooperative or a non-cooperative strategy when designing interest rate control or money supply control in open economies.

\section{A General Derivation of a Central Bank's Optimal Interest Rate Policy}

In the aftermath of the current financial crisis the central banks will probably switch back to interest rate control (see above). Therefore, in the meantime, it is very important to develop a decision logical and solid basis to explain interest rate control instead of using ad hoc interest rate rules like the Taylor rule. Such an optimization approach for central banks is described below.

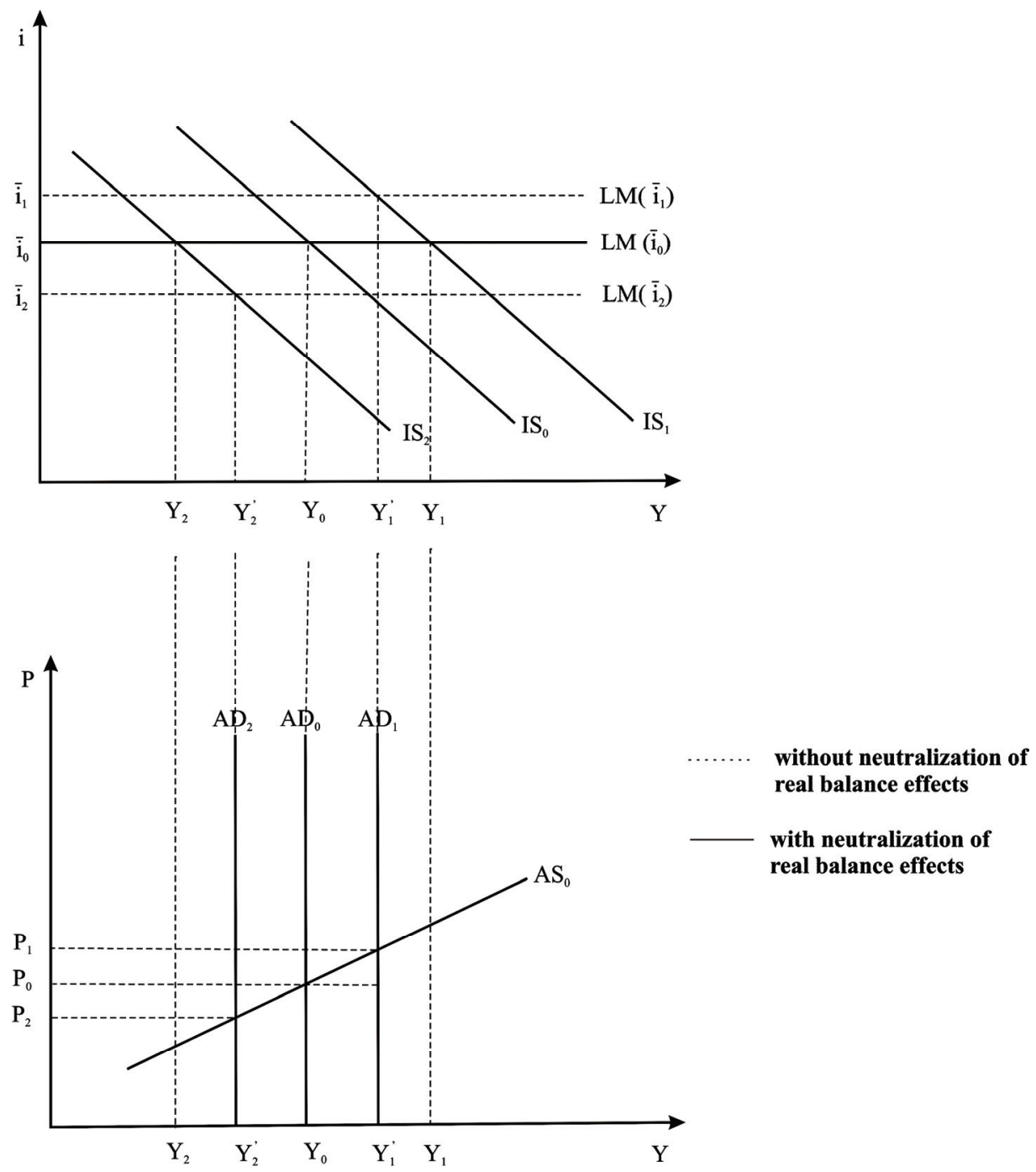

Figure 6. Expansive/contractive fiscal policy in the case of interest rate control. 
What is rarely noticed is that Poole [1] (pp. $204 \mathrm{ff}$.), in his much-noticed contribution, already worked successfully with the instrument of an overall economic welfare loss function. In this context, he minimized the expected value of the squared deviation between the current output and the target output (output gap) with regard to applying interest rates as a policy instrument and, alternatively, with regard to money supply control.

If the central bank chooses the nominal interest rate as the "operating target", then it has direct influence on the real output given the equilibrium condition for the goods market. If, for the medium-run, the real interest rate in the IS curve $(r)$ is replaced by the nominal interest rate and inflation expectations $\left(\pi^{e}\right)$ in accordance with the Fisher interest rate parity $\left(r=i-\pi^{e}\right)$, and the nominal interest rate is replaced by the interest rate target (see Equation (4)), the following is obtained:

$$
Y=\alpha\left(A_{a}+h \pi^{e}-h i^{*}\right)
$$

In the case of given autonomous absorption and given inflation expectations, an exogenous interest rate reduction (increase) leads to a rising (falling) real output. This real output level $Y$ determines, in turn, the inflation rate, as can easily be seen from the dynamized AS function (cf. Dornbusch/Fischer [9]):

$$
\pi=\gamma\left(Y-Y^{n a t}\right)+\pi^{e}
$$

If income increases, inflation also rises c. p. (i.e. with an unchanged level of the natural output) within the same period.

If the central bank pursues interest rate control, it influences the output via the correlation of the IS curve (Equation (8)) and, in a second step, the level of inflation via the correlation of the AS curve. The transmission channels of monetary policy can be directly derived by inserting Equation (8), the medium-run IS curve, into (9), the dynamized AS curve:

$$
\pi(i)=\gamma \alpha A_{a}+(1+\gamma \alpha h) \pi^{e}-\gamma Y^{n a t}-\gamma \alpha h i
$$

The lower (higher) the interest rate is, the higher (lower) the inflation rate will be-for a given autonomous absorption, given inflation expectations, and a given natural output level. Accordingly, it is easier for the central bank to achieve a low inflation rate, the lower the inflation expectations are and the higher the natural output level is.

The central bank now minimizes a welfare loss function $\mathrm{L}$ by solving the following problem:

$$
\begin{aligned}
& \min _{i} L \text { where } \\
& L[\pi(i), Y(i)]=\theta \pi^{2}+(1-\theta)\left(Y-Y^{n a t}-\Delta\right)^{2},
\end{aligned}
$$

and $\theta$ denotes a weighting coefficient, $\Delta$ an externality.

The central bank will thus choose an interest rate to minimize the welfare losses due to inflation and output fluctuations. For simplification, the target inflation rate will be determined to be equal to zero. The output target envisaged by the central bank corresponds to the natural output $Y^{\text {nat }}$ plus an externality $\Delta$. The latter reflects the usual assumption of some frictions due to taxes, imperfect competition etc. The central bank then tries to overcome these inefficiencies by a higher output target. The specific interest rate $i^{*}$ which minimizes the welfare losses (for an overview of optimizing approaches to gain policy rules cf. Walsh [11]) is given by:

$$
\begin{aligned}
i^{*}= & \frac{1}{h} A_{a}-\frac{1}{\alpha h} Y^{n a t} \\
& +\left[1+\frac{\gamma^{\theta}}{\alpha h \gamma^{2} \theta+\alpha h(1-\theta)}\right] \pi^{e} \\
& -\left[\frac{(1-\theta)}{\alpha h \gamma^{2} \theta+\alpha h(1-\theta)}\right] \Delta
\end{aligned}
$$

If we take Equations (12) and (10) together, we get the optimal inflation rate:

$$
\pi\left(i^{*}, \pi^{e}\right)=\left[\frac{(1-\theta)}{\gamma^{2} \theta+(1-\theta)}\right]\left[\pi^{e}+\gamma \Delta\right]
$$

The most significant determinants of the inflation rate are inflation expectations and the externality. Both parameters have a positive impact on inflation.

Any optimal inflation level which satisfies Equation (13) is basically feasible. However, we should account for rational expectations as a standard consistency requirement of any model with forward looking behavior. In line with the well-known Lucas critics it is common practice to interpret the equilibrium under rational expectations as the long-run outcome of the economy and thus as a state where policy measures are ineffective since anticipation errors no longer occur. To find out the optimal inflation rate under rational expectations we simply add the condition $\pi=\pi^{e}$ to (13) and get:

$$
\hat{\pi}\left(i^{*}\right)=\frac{(1-\theta)}{\gamma \theta} \Delta
$$

Figure 7 is an illustration of the rational expectation equilibria. The equilibria are all points where our optimal inflation function $\pi\left(i^{*}, \pi^{e}\right)$ crosses the dashed bisecting line $\left(\pi=\pi^{e}\right)$.

The plot contains three different values for the weighting coefficient $\theta$ : The upper bound $\theta=1$ (priority exclusively on fighting inflation), the lower bound $\theta=0$ (priority exclusively on preventing output fluctuations), and an intermediate value for $\theta$. As we can see, for $\theta=1$ the inflation function becomes horizontal, which leads to the null inflation equilibrium. As the central bank has the highest possible preference for price stability, the audi- 
ence is convinced enough to believe it $\left(\pi^{*}=\pi^{e}=0\right)$. With smaller $\theta$, both intercept and slope of the inflation function rise, which lead to higher inflation rates (and expected inflation rates respectively) in equilibrium. For $\theta=0$ we get a somewhat extreme result: Both functions run in parallel, which means that they never intersect: The limit $\theta \rightarrow 0$ implies that inflation and expectations together build up to infinity: $\pi=\pi^{e} \rightarrow \infty$. In this case, the central bank completely ignores price stability and just concentrates on output stabilization. The audience takes this total neglect into account and expects an extreme inflation path.

If we take Equations (8) and (12) together, we get the optimal output level:

$$
Y\left(i^{*}, \pi^{e}\right)=Y^{n a t}+\frac{\Delta-\left(\Delta+\gamma \pi^{e}\right) \theta}{\gamma^{2} \theta+(1-\theta)}
$$

The natural level $Y^{\text {nat }}$ represents the benchmark of output fluctuations. Further important parameters determining the optimal output level are again inflation expectations and the externality. However, each of the two influences output by a different sign: The impact of the externality on output is positive which should be quite clear since $\Delta$ is a positive externality and the central bank tries to adjust upwards (if $\theta<1$ ). Higher inflation expectations however curtail the output level, since a rising $\pi^{e}$ comes with a higher interest rate.

To provide some benchmark solutions we now calcu- late the optimal interest rate $i^{*}$, the optimal inflation rate $\pi^{*}$ and the optimal output level $Y^{*}$ for the extreme constellations of the weighting factor upper bound $\theta=1$ (priority exclusively on fighting inflation) and lower bound $\theta=0$.

For $\theta=1$, we obtain:

$$
i_{\theta=1}^{*}=\frac{1}{h} A_{a}-\frac{1}{\alpha h} Y^{n a t}+\left[1+\frac{1}{\alpha h \gamma}\right] \pi^{e}
$$

For the output and the inflation rate, the values induced with this interest rate are:

$$
Y\left(i_{\theta=1}^{*}\right)=Y^{n a t}-\frac{1}{\gamma} \pi^{e} \text { and } \pi\left(i_{\theta=1}^{*}\right)=0 .
$$

We obtain these values by inserting Equation (13) into Equations (8) and (10) respectively for given inflation expectations. Accordingly, if the central bank places its priority exclusively on a lower inflation rate, then it will achieve an inflation rate amounting to zero. However, the resulting output is — as can be seen from (17) — below its natural level. For the opposite case $\theta=0$, we obtain:

$$
i_{\theta=1}^{*}=\frac{1}{h} A_{a}-\frac{1}{\alpha h}\left(Y^{n a t}+\Delta\right)+\pi^{e}
$$

For the output and the inflation rate, the values induced with this interest rate are:

$$
Y\left(i_{\theta=1}^{*}\right)=Y^{n a t}-\Delta \text { and } \pi\left(i_{\theta=1}^{*}\right)=\Delta \gamma+\pi^{e} .
$$

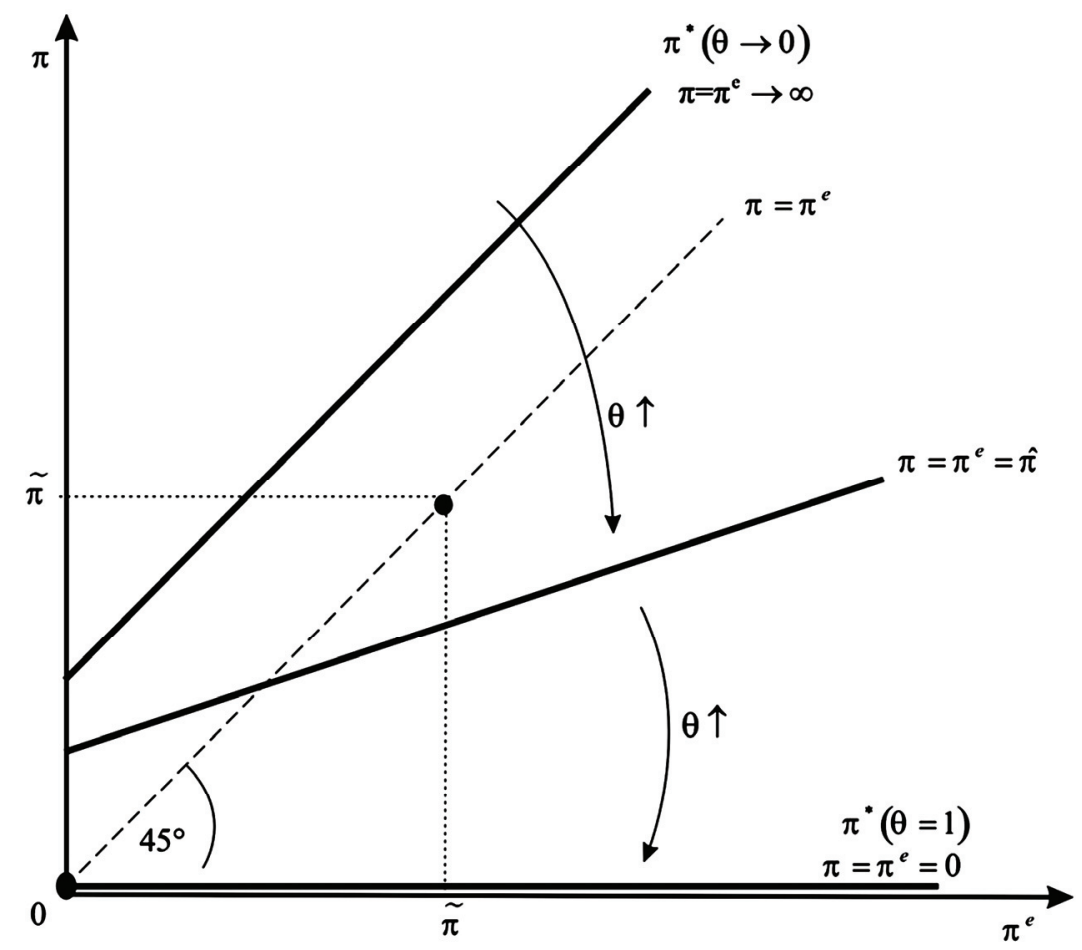

Figure 7. Rational expectation equilibria. 
A central bank which exclusively pursues the objective of preventing deviations from the natural output will reach this target in the short-run: The output then exceeds its natural state by the externality $\Delta$. The inflation rate is clearly positive: Inflation is partly composed of the central banks' incentive to overcome the inefficiency $(\Delta)$ on the one hand and of inflation expectations on the other hand $\left(\pi^{e}\right)$. In this scenario, the short-run interest rate is lower (cf. with expression (16)), because a low interest rate is the means for extremely expansive monetary policy. Both benchmark solutions discussed so far are short-run. In the long-run, the strategy of the central bank will be anticipated by the audience so that the optimal interest rate and the output must be in accordance with the inflation rate under rational expectations $\hat{\pi}$ (cf. Equation (14)). The corresponding output rate is clearly the natural output level $Y^{\text {nat }}$ (for all $\theta$ ), so in the long-run the central bank's effort to compensate the externality and to push the output beyond the natural level will simply evaporate. The optimal interest rate is given by:

$$
i^{*}(\hat{\pi})=\frac{1}{h} A_{a}-\frac{1}{\alpha h} Y^{n a t}+\hat{\pi} \text { with } \hat{\pi}=\frac{(1-\theta)}{\gamma \theta} \Delta
$$

Now the model is nearly complete and we add the last component. The derived values for the inflation rate and the output must at all time be compatible with the money market equilibrium (LM curve). This poses no problem, because the money supply will automatically adapt itself to changes in the interest rate (triggered by the central bank). In order to describe this constraint adequately, the dynamized version of the LM curve (Equation (2)) will be used (cf. Dornbusch/Fischer [9] and McCallum [12]):

$$
m-\pi=k\left(Y_{t}-Y_{t-1}\right)-j\left(i_{t}-i_{t-1}\right)
$$

The rate of change in the nominal money supply $m$ (monetary expansion or contraction) will adapt itself in such a way that the change in the real money supply (left-hand side of Equation (20)) corresponds to the change in the real money demand (right-hand side of Equation (20)). If we take into account that, in the case of interest rate control, the variables $\pi$ und $Y$ result from Equations (8) and (10) respectively, and if we insert the optimal interest rate from Equation (12) into Equation (20), we obtain the change in the nominal money supply as a function of the weighting coefficient $\theta$. For the two extreme cases of exclusive priority placed on inflation containment $(\theta=1)$ and/or to the minimization of output fluctuations $(\theta=0)$, we obtain for $m$ :

$$
\begin{aligned}
m_{\theta=1}= & \left(\frac{j}{\alpha h}+k\right) Y^{n a t}+j i_{t-1} \\
& -\frac{j}{h} A_{a}-k Y_{t-1}-\left(\frac{j}{\alpha h \gamma}+\frac{k}{\gamma}+j\right) \pi^{e}
\end{aligned}
$$

$$
\begin{aligned}
m_{\theta=1}= & \left(\frac{j}{\alpha h}+k\right) Y^{n a t}+j i_{t-1} \\
& -\frac{j}{h} A_{a}-k Y_{t-1}+\left(\frac{j}{\alpha h}+k+j\right) \Delta \\
& +(1-j) \Delta \pi^{e}
\end{aligned}
$$

It can be seen from the last term of both equations that, in the case of an exclusive inflation target (Equation (21)), the higher the inflation expectations are, the lower the monetary expansion will be. In other words, the inflation expectations must be "broken" in this case. However, in the case of an exclusive output target (Equation (22)), the monetary expansion will rise in step with the inflation expectations. If the central bank does not pay any attention to the costs resulting from inflation, the inflation expectations will merely be "accommodated". Figure 8 graphically represents the entire situation in a $(\pi, Y)$ chart. In the long-run the equilibrium is characterized by rational expectations. In this case the economy reaches its natural output level $Y^{\text {nat }}$ for all levels of (expected) inflation. The vertical line $\hat{\pi}(\theta)$ thus represents the long-run Phillips-Curve.

The set of curves represent indifference curves for various values of the loss function $L$. An arbitrary indifference curve with welfare loss $\bar{L}$ and weighting coefficient $\theta$ can easily be determined by rearranging objective function (11) to $\pi$.

$$
\pi(Y)=\sqrt{\frac{\bar{L}}{\theta}-\frac{(1-\theta)}{\theta}\left(Y-Y^{n a t}-\Delta\right)^{2}}
$$

A low weighting coefficient $\left(\theta^{L}\right)$ for the inflation target (e.g. $\theta=0.2)$ corresponds to the set of strongly concave indifference curves. Accordingly $\theta^{\mathrm{H}}$ (e.g. $\theta=0.8$ ) corresponds to weakly concave indifference curves. The strong concavity for a low priority on inflation can be explained by the fact that the central bank accepts a relatively high rise in the inflation rate in order to come somewhat closer to achieving target output $Y^{\text {nat }}+\Delta$. Consequently, for a high priority on inflation, the indifference curves are weakly concave, because in this case the central bank accepts relatively strong deviations from the target output in order to achieve a slight reduction in the inflation rate. The straight lines with negative slope represent the money market equilibrium condition: They describe all combinations of inflation rate and income which are consistent with a specific level of monetary expansion $\mathrm{m}$. In this context, value $m_{\theta}=1$ corresponds to the constellation for $\theta=1$ (see Equation (21) and point A in Figure 8) and, consequently, $m_{\theta}=0$ corresponds to the constellation for $\theta=0$ (see Equation (22) and point B in Figure 8). We obtain the straight line for a specific weighting coefficient $\theta$ by inserting $m(\theta)$ together with $i^{*}$ into Equation (17) and by rearranging to $\pi$. In this way, being a function of the chosen weighting coefficient $\theta$, 


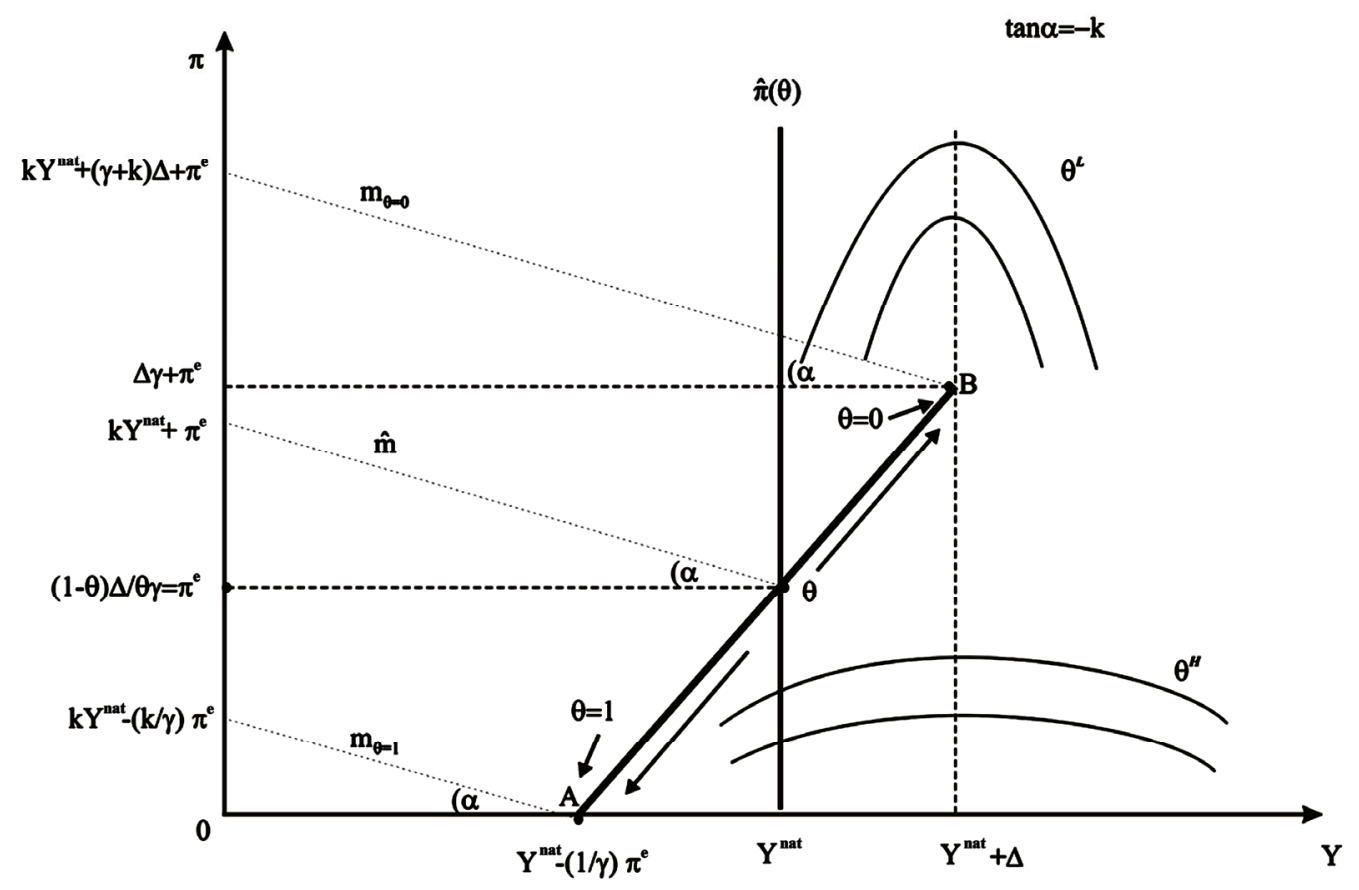

Figure 8. Optimal monetary policy in the case of interest rate control.

all $(\pi, Y)$ combinations achievable by monetary policy can be described by the straight line with positive slope $\overline{\mathrm{AB}}$. This line represents the (short-run) Phillips-Curve. A situation represented by Equation $(17)(\theta=1)$ can be found at point $\mathrm{A}$ : The inflation rate is zero, but the output is lower than the natural output. The change in money supply occurs in a contractive manner. The intercept of the money market line $m_{\theta}=1$ is below the inflation expectations; thus, a contractive monetary policy must "break" the inflation expectations in order to be able to achieve the desired zero inflation rate. The situation described by Equation (19) $(\theta=0)$ exists at point B: Here the inflation rate is exactly at the level of the inflation expectations and, accordingly, also the achieved output is at its natural level. In this case, the intercept of the money market line $m_{\theta}=0$ is above the inflation expectations. The output is higher than in the "natural state": The money supply will adapt itself in such a way that, first, the money demand $\left(k Y^{n a t}+(\gamma+k) \Delta\right)$ is satisfied and, second, inflation expectations $\left(\pi^{e}\right)$ are accommodated.

\section{Conclusions}

The IS-LM framework originating from Keynes' disciples Alvin Hansen and John Hicks can-as has been demonstrated by this contribution-be appropriately extended to the case of interest rate control conducted by central banks without having to abandon the equilibrium concept of the IS-LM analysis, as has been vehemently maintained by advocates of "New Keynesian Macroeconomics" for years. Especially in times of financial and economic crises (when central banks possibly switch their monetary policy instruments back to quantitative easing), it seems to be very helpful to be able to display both interest rate control and money supply control within one single model framework. For a comprehensive-rather than simply partial - analysis of the macroeconomics of monetary policy it is objectionable to blind out the money market as such. Our analysis has shown that retaining the LM curve is both practical and indispensable for didactic and analytical reasons.

In addition, it is possible to design the dynamic version of the IS-LM framework in such a way that it is compatible with the optimization behavior of central banks in the case of interest rate control and that it provides very general determining reasons for choosing the key interest rate instead of following a policy rule.

Finally, it is easy to extend our framework to illustrate specific problems of optimal monetary policy, e.g. time inconsistency (cf. Kydland/Prescott [13]).

Our model confirms the impression that macroeconomic analysis should continue to work with a somewhat generalized and consistent framework-instead of putting aside the LM curve i.e. the explicit money market equilibrium as done in Graf Lambsdorff/Engelen [14].

\section{References}

[1] W. Poole, "Optimal Choice of Monetary Policy Instruments in a Simple Stochastic Macro Model," Quarterly 
Journal of Economics, Vol. 84, No. 2, May 1970, pp. 197-216.

[2] D. Romer, "Short-Run Fluctuations," University of California, Berkeley, August 2002.

[3] F. L. Sell, "Zins- und Geldmengensteuerung in Der offenen Volkswirtschaft," WISU-Das Wirtschaftsstu-dium, Vol. 35, No. 3, May 2006, pp. 363-372 and 379-380.

[4] R. Clarida, J. Galí and M. Gertler, "The Science of Monetary Policy: A New Keynesian Perspective," Journal of Economic Literature, Vol. 37, No. 4, December 1999, pp. 1661-1707.

[5] D. Romer, "Keynesian Macroeconomics without the LM Curve," Journal of Economic Perspectives, Vol. 14, No. 2, Spring 2000, pp. 149-169.

[6] C. E. Walsh, "Teaching Inflation Targeting: An Analysis for Intermediate Macro", Journal of Economic Education, Vol. 33, No. 4, 2002, pp. 333-346.

[7] B. Friedman, "The LM Curve: A Not-So-Fond Farewell,"
NBER Working Paper Series, No. 10123, November 2003.

[8] O. Blanchard, "Macroeconomics," 4th Edition, Prentice Hall, 2006.

[9] R. Dornbusch, S. Fischer and R. Startz, "Macroeconomics," 10th Edition, McGraw-Hill/Irwin, New Delhi, 2007.

[10] F. L. Sell and S. Kermer, "William Poole in der Offenen Volkswirtschaft," Kredit und Kapital, Vol. 41, No. 4, 2008, pp. 467-500.

[11] C. E. Walsh, "Monetary Theory and Policy," 2nd Edition, The MIT Press, Cambridge, 2003.

[12] B. T. McCallum, "Monetary Economics-Theory and Policy," Macmillan Publishing, New York, 1989.

[13] F. E. Kydland and E. C. Prescott, "Rules rather than Discretion: The Inconsistency of Optimal Plans," Journal of Political Economy, Vol. 85, No. 3, April 1977, pp. 473-491.

[14] J. G. Lambsdorff and C. Engelen, "Das Keynesi- anische Konsensmodell," Wirtschaftswissenschaft- liches Studium (WiSt), Vol. 36, No. 7, August 2007, pp. 387-393. 